\title{
WHICH IS THE BETTER CHOICE FOR AIRWAY MAINTENANCE IN PAEDIATRIC PATIENTS: PROSEAL LMA OR I-GEL?
}

Avanish Bhandary1, Sushanth Unnikrishnan ${ }^{2}$

${ }_{1}^{1}$ Associate Professor, Department of Anaesthesia and Critical Care, K. S. Hegde Medical Academy. 2Junior Resident, Department of Anaesthesia and Critical Care, K. S. Hegde Medical Academy.

\section{ABSTRACT}

\section{CONTEXT}

The major responsibility of the anaesthesiologist is to provide adequate ventilation to the patient. Supraglottic airway devices such as the I-Gel and ProSeal LMA are well studied in adults. However, there is lack of consensus in paediatric patients. Such studies are particularly important in children, as they are more vulnerable to complications related to the use of cuffed supraglottic airway devices.

\section{AIMS}

To compare ProSeal LMA with I-Gel in children.

\section{SETTINGS AND DESIGN}

STUDY DESIGN: Randomised, controlled, prospective study.

STUDY SETTING: K. S. Hegde Hospital, Mangalore, India.

\section{METHODS AND MATERIAL}

80 ASA physical status 1 and 2 patients aged 4-15 yrs. scheduled to undergo elective surgery under general anaesthesia were randomly allocated to have LMA-ProSeal or I-Gel for airway maintenance. We compared the ease of insertion, clinical and fiberoptic assessment of proper positioning of the device.

\section{STATISTICAL ANALYSIS USED}

The data was collected and managed using Microsoft Excel, Chi square test and McNemar's test.

\section{RESULTS}

We found that the mean insertion time for LMA-ProSeal and I-Gel were 14.39 seconds and 12.13 seconds respectively. Mean insertion time was significantly less in $\mathrm{I}-\mathrm{Gel}$ with $(\mathrm{P}=0.001)$. The number of $1^{\text {st }}$ attempt success rates were similar in both groups $(\mathrm{p}=0.22)$. There was no significant difference in the fiberoptic view and the number of complications in both the groups.

\section{CONCLUSIONS}

We conclude that PLMA requires more time for insertion compared to I-Gel. However, the final cuff position of PLMA is similar to that of I-Gel as assessed by fiberoptic bronchoscopy. So both devices can be used effectively in children.

\section{KEYWORDS}

PLMA, I-Gel, Ease of Insertion, Fiberoptic, Paediatrics.

HOW TO CITE THIS ARTICLE: Bhandary A, Unnikrishnan S. Which is the better choice for airway maintenance in paediatric patients: proseal LMA or I-GEL? J. Evolution Med. Dent. Sci. 2016;5(47):2980-2983, DOI: 10.14260/jemds/2016/695

\section{INTRODUCTION}

The major responsibility of the anaesthesiologist is to provide adequate ventilation to the patient. Management of the airway has come a long way from the first reported use of Endotracheal Tube (ET) by Dr Macewan (1880) to the present day usage advanced supraglottic devices. ${ }^{1}$

Supraglottic airway devices such as the I-Gel and ProSeal LMA are well studied in adult patients. However, there is lack of consensus regarding supraglottic device of choice in paediatric patients. Such studies are particularly important in children, as they are more vulnerable to complications related to the use of cuffed supraglottic airway devices. $^{2}$

Financial or Other, Competing Interest: None.

Submission 02-02-2016, Peer Review 05-03-2016,

Acceptance 11-03-2016, Published 11-06-2016.

Corresponding Author:

Dr. Avanish Bhandary,

Associate Professor,

Department of Anaesthesia and Critical Care,

K. S. Hegde Medical Academy,

Mangalore.

E-mail: avanishbhandary@gmail.com

DOI: 10.14260/jemds/2016/695

\section{AIM OF THE STUDY}

To compare and evaluate ProSeal LMA with I-Gel in paediatric patients undergoing general anaesthesia.

\section{OBJECTIVES OF STUDY}

To assess PLMA and I-Gel in paediatric patients undergoing general anaesthesia in terms of:

- Ease of insertion.

- Clinically assess proper position of the device.

- Fiberoptically assess and grade the anatomic position of the device, after placement and before removal.

\section{SAMPLE SELECTION}

Selection Method

Patients were randomly assigned into two groups by closed envelope method.

Group A: 40 patients in whom LMA ProSeal was used.

Group B: 40 patients in whom I-Gel was used.

\section{Inclusion Criteria}

- $\quad$ Patients belonging to ASA physical status I and II.

- $\quad$ Patients aged between 4 to 15 yrs.

- $\quad$ Elective surgeries. 


\section{Exclusion Criteria}

- Parent/Guardian refusal.

- Patients undergoing surgery in position other than supine or lithotomy position.

- $\quad$ Patients undergoing airway surgeries.

- Patients with predicted difficult airway.

- Patients with high risk of aspiration.

- Inability to secure intravenous access before induction.

- Surgeries in which muscle relaxant or endotracheal intubation is required.

\section{PROCEDURE}

On approval from the Institutional Ethical Committee, informed consent for the study was obtained from patient's parents/guardian. All patients were evaluated for different airway parameters (Mouth opening, Mallampati grading, temporomandibular joint thyromental distance). Patients were randomly assigned into either group A or group B by closed envelop method.

All the patients were kept nil by mouth as per standard guidelines. All patients were pre-medicated with oral midazolam $0.5 \mathrm{mg} / \mathrm{kg}$ on the previous night and morning.

After shifting patients to operation theatre, an intravenous access was secured. Preoperative baseline vitals were recorded and crystalloid infusion was started. Inj. fentanyl $2 \mu \mathrm{g} / \mathrm{kg}$ was given over $30 \mathrm{~s}$ followed by preoxygenation with $100 \%$ oxygen for 3 minutes. Inj. Propofol 3 $\mathrm{mg} / \mathrm{kg}{ }^{3}$ was given for induction of anaesthesia. No neuromuscular blocking agent was used. Additional dose of propofol was used if needed to achieve adequate jaw relaxation before insertion of device. Device of appropriate size according to weight was selected in the individual groups. ${ }^{4}$ Device was inserted as per standard insertion technique. 5

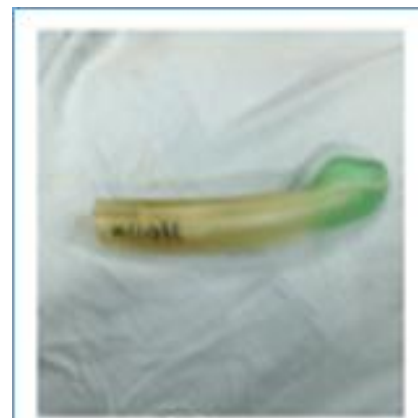

(a)

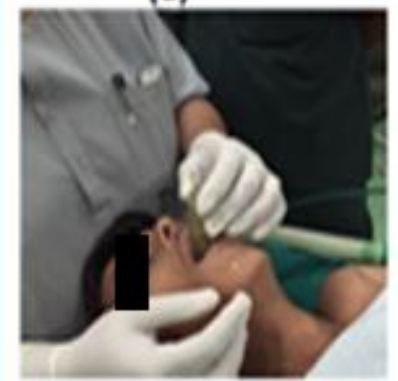

(c)

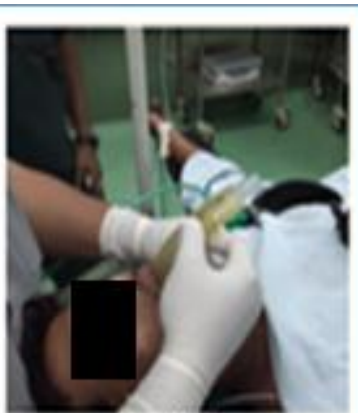

(b)

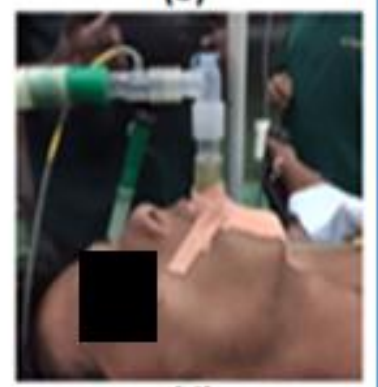

(d)

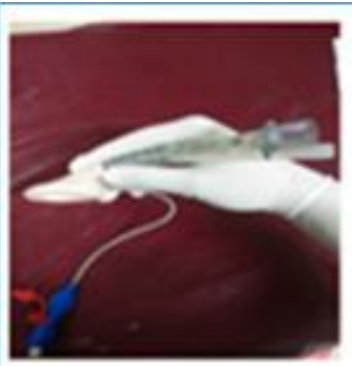

(a)

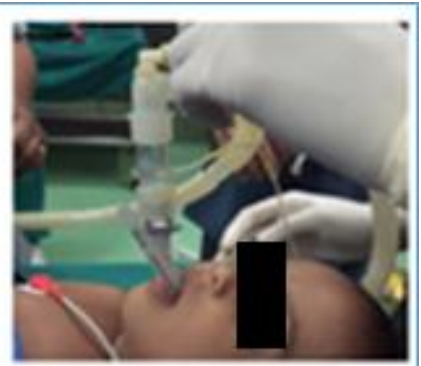

(b)

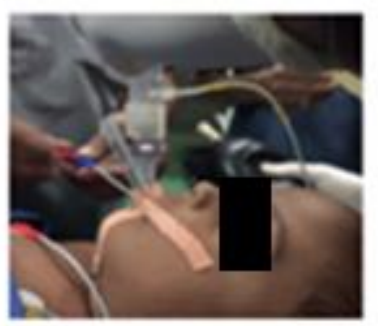

(c)

Device insertion time was measured from the moment the face mask is taken away from the patient's face until ventilation is resumed. Ease of insertion was based on the number of attempts required and the time required for insertion of the device. ${ }^{6}$

Anaesthesia was maintained with oxygen, nitrous oxide in 50:50 ratio and sevoflurane $1-2 \%$. Proper positioning and airway patency was confirmed by (a) Adequate chest rise with manual ventilation, (b) Reservoir bag refill during expiration, (c) Absence of leak with positive pressure ventilation, (d) Square wave Capnograph. The device was reinserted if the above criteria is not fulfilled. Need for more than two attempts of device insertion was considered as failure and it was documented following which the patient was intubated. While continuing ventilation, the fiberoptic bronchoscope was inserted through the swivel connector, so that the position was at the junction between the shaft and the mask (Length of fiberoptic bronchoscope insertion was calculated before insertion by measuring the length of the device shaft).

The larynx was visualized and graded according to the criteria proposed by Park C. ${ }^{7}$ as shown below:

Grade 1: Larynx only seen.

Grade 2: Larynx and epiglottis posterior surface seen.

Grade 3: Larynx, and epiglottis tip or anterior surface seen (Visual obstruction of epiglottis to larynx $<50 \%$ ).

Grade 4: Epiglottis down-folded, and its anterior surface seen (Visual obstruction of epiglottis to larynx: $>50 \%$ ).

Grade 5: Epiglottis down-folded and larynx not seen directly.

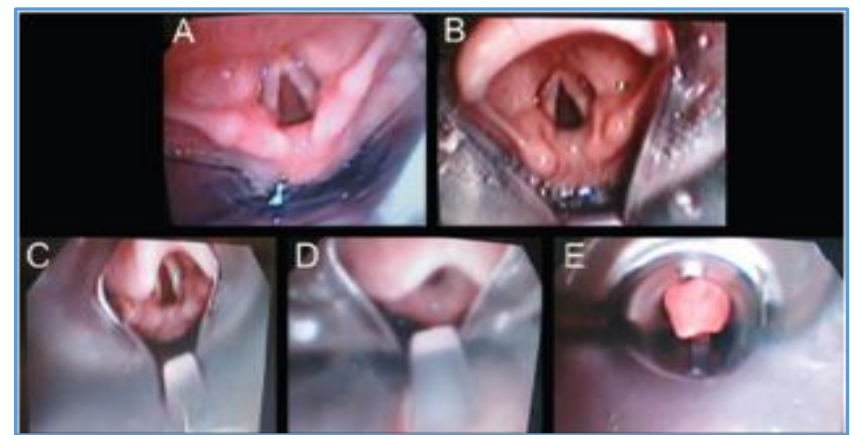

A - Grade 1, B - Grade 2, C-Grade 3, D - Grade 4, E - Grade 5 
Fiberoptic bronchoscope Grading after device insertion and before removal

At the end of the surgery, the position of the device was reassessed with the fiberoptic bronchoscope before reversal of anaesthesia. The device was removed when the patient was fully awake. The removed device was inspected for the presence of blood. After 5 minutes of observation, patients were transported to the recovery room and monitored for postoperative complications.

\section{DATA ANALYSIS}

Descriptive and inferential statistical analysis has been carried out in the present study. Results on continuous measurements are presented on Mean \pm SD (Min-Max) and results on categorical measurements are presented in number and percentage (\%). Significance is assessed at $5 \%$ level of significance. The following assumptions on data is made, Assumptions: 1. Dependent variables should be normally distributed, 2 . Samples drawn from the population should be random, cases of these samples should be independent. Student ' $t$ ' test (two tailed, independent) has been used to find the significance of study parameters on continuous scale between two groups, Intergroup analysis on metric parameters. Levene's test for homogeneity of variance has been performed to assess the homogeneity of variance. Chi-square/Fisher Exact test has been used to find the significance of study parameters on categorical scale between two or more groups. Data was analysed using IBM SPSS statistics for windows, Version 20.0. Armonk, NY: IBM Corp.

\section{RESULTS}

A total of 80 children planned at the K. S. Hedge Hospital, Mangalore, for elective day surgery with general anaesthesia not necessitating tracheal intubation were designated. There were no statistically significant differences in demographic characteristics between the groups.

\begin{tabular}{|c|c|c|c|c|}
\hline \multirow{2}{*}{$\begin{array}{c}\text { Age in } \\
\text { Years }\end{array}$} & \multicolumn{2}{|c|}{ ProSeal LMA } & \multicolumn{2}{c|}{ I-Gel } \\
\cline { 2 - 5 } & Number & $\mathbf{\%}$ & Number & $\mathbf{\%}$ \\
\hline $4-9$ & 18 & 45.0 & 20 & 50.0 \\
\hline $10-15$ & 22 & 55.0 & 20 & 50.0 \\
\hline Total & $\mathbf{4 0}$ & $\mathbf{1 0 0 . 0}$ & $\mathbf{4 0}$ & $\mathbf{1 0 0 . 0}$ \\
\hline Mean \pm SD & $\mathbf{8 . 7 1} \pm \mathbf{5 . 5 4}$ & $\mathbf{8 . 2 4} \pm \mathbf{5 . 9 0}$ \\
\hline \multicolumn{4}{|c|}{ Age Distribution } \\
\hline
\end{tabular}

Samples are age matched with $\mathrm{P}=0.311$.

\begin{tabular}{|c|c|c|c|c|}
\hline \multirow{2}{*}{ Gender } & \multicolumn{2}{|c|}{ ProSeal LMA } & \multicolumn{2}{c|}{ I-Gel } \\
\cline { 2 - 5 } & Number & \% & Number & \% \\
\hline Male & 19 & 47.0 & 18 & 45.0 \\
\hline Female & 21 & 53.0 & 22 & 55.0 \\
\hline Total & $\mathbf{4 0}$ & $\mathbf{1 0 0 . 0}$ & $\mathbf{4 0}$ & $\mathbf{1 0 0 . 0}$ \\
\hline \multicolumn{4}{|c|}{ Gender Distribution } \\
\hline
\end{tabular}

Samples are gender matched with $\mathrm{P}=0.887$.

\begin{tabular}{|c|c|c|c|c|}
\hline \multirow{2}{*}{$\begin{array}{c}\text { ASA Physical } \\
\text { Status }\end{array}$} & \multicolumn{2}{|c|}{ ProSeal LMA } & \multicolumn{2}{c|}{ I-Gel } \\
\cline { 2 - 5 } & Number & $\mathbf{\%}$ & Number & \% \\
\hline Grade I & 33 & 81.0 & 34 & 84.0 \\
\hline Grade II & 7 & 19.0 & 6 & 16.0 \\
\hline Total & 40 & 100.0 & 40 & 100.0 \\
\hline \multicolumn{5}{|c|}{ ASA Physical Status } \\
\hline
\end{tabular}

ASA physical status is statistically similar in two groups with $\mathrm{P}=0.71$.

\begin{tabular}{|c|c|c|c|c|}
\hline \multirow{2}{*}{ Weight } & \multicolumn{2}{|c|}{ ProSeal LMA } & \multicolumn{2}{c|}{ I-Gel LMA } \\
\cline { 2 - 5 } & Number & $\mathbf{\%}$ & Number & \% \\
\hline$<15$ & 3 & 7.5 & 2 & 5.0 \\
\hline $15-30$ & 15 & 37.5 & 17 & 42.5 \\
\hline $30-50$ & 15 & 37.5 & 10 & 25.0 \\
\hline$>50$ & 7 & 17.5 & 11 & 27.5 \\
\hline Total & $\mathbf{4 0}$ & $\mathbf{1 0 0 . 0}$ & $\mathbf{4 0}$ & $\mathbf{1 0 0 . 0}$ \\
\hline Mean \pm SD & $\mathbf{2 2 . 1 2 \pm 5 . 5 3}$ & $\mathbf{2 4 . 7 8 \pm 5 . 7 8}$ \\
\hline \multicolumn{4}{|c|}{ Weight (kg) } \\
\hline
\end{tabular}

Mean weight is statistically similar in two groups with $\mathrm{P}=0.411$.

Insertion time was shorter for Group - I-Gel than Group ProSeal LMA $(12.13 \pm 8.00$ vs $14.39 \pm 9.56$ 's, respectively, $\mathrm{p}=0.01$ ).

\begin{tabular}{|c|c|c|c|c|}
\hline \multirow{2}{*}{ Duration (s) } & \multicolumn{2}{|c|}{ I-Gel } & \multicolumn{2}{c|}{ ProSeal LMA } \\
\cline { 2 - 5 } & Number & $\mathbf{\%}$ & Number & \% \\
\hline $1-10$ & 20 & 50.0 & 16 & 40.0 \\
\hline $11-20$ & 11 & 27.5 & 14 & 35.0 \\
\hline $21-30$ & 7 & 17.5 & 8 & 20.0 \\
\hline$>30$ & 2 & 5.0 & 2 & 5.0 \\
\hline Total & $\mathbf{4 0}$ & $\mathbf{1 0 0 . 0}$ & $\mathbf{1 0 0}$ & $\mathbf{1 0 0 . 0}$ \\
\hline Mean \pm SD & $\mathbf{1 2 . 1 3 \pm 8 . 0 0}$ & $\mathbf{1 4 . 3 9 \pm 9 . 5 6}$ \\
\hline \multicolumn{3}{|c}{ Time Taken for Device Insertion } \\
\hline
\end{tabular}

Mean duration is significantly less in I-Gel with $\mathrm{P}=0.01$.

The first attempt success rate was high for both devices (80\% for Group I-Gel and 85\% for Group-ProSeal, p=0.40).

\begin{tabular}{|c|c|c|c|c|}
\hline \multirow{2}{*}{$\begin{array}{c}\text { Insertion } \\
\text { Attempts }\end{array}$} & \multicolumn{2}{|c|}{ ProSeal LMA } & \multicolumn{2}{c|}{ I-Gel LMA } \\
\cline { 2 - 5 } & Number & $\mathbf{\%}$ & Number & $\mathbf{\%}$ \\
\hline 1.00 & 32 & 80.0 & 34 & 85.0 \\
\hline 2.00 & 8 & 20.0 & 6 & 15.0 \\
\hline Total & 40 & 100.0 & 40 & 100.0 \\
\hline \multicolumn{3}{|c}{ Number of Insertion Attempts } \\
\hline
\end{tabular}

All the failed insertion first attempts in both groups were successfully reinserted in second attempt.

There were no statistically significant differences with regard to ease of insertion.

Clinical criteria of placement were satisfactory in $75 \%$ patients with I-Gel after first attempt of insertion; 4 patients had leak and clinically satisfactory placement was seen in all patients after second attempt. In PLMA group, clinical criteria were satisfactory in $83 \%$ patients after first attempt, 3 patients had leak and clinically satisfactory placement was seen in all patients after second attempt $(p=0.4)$.

Fiberoptic grading according to Park $\mathrm{C}$ criteria was statistically similar in two groups $(\mathrm{P}=0.731)$.

\begin{tabular}{|c|c|c|c|c|c|}
\hline Fiberoptic & \multicolumn{2}{|c|}{ ProSeal LMA } & \multicolumn{2}{c|}{ I-Gel } & P \\
\cline { 2 - 5 } Grading & Number & $\mathbf{\%}$ & Number & $\mathbf{\%}$ & value \\
\hline Grade 1 & 10 & 25.0 & 9 & 24.0 & 0.869 \\
\hline Grade 2 & 20 & 50.0 & 17 & 44.0 & 0.395 \\
\hline Grade 3 & 8 & 20.0 & 10 & 25.0 & 0.397 \\
\hline Grade 4 & 3 & 5.0 & 4 & 7.0 & 0.194 \\
\hline Grade 5 & 0 & 0 & 0 & 0 & - \\
\hline Total & $\mathbf{4 0}$ & $\mathbf{1 0 0 . 0}$ & $\mathbf{4 0}$ & $\mathbf{1 0 0 . 0}$ & - \\
\hline \multicolumn{7}{|c|}{ Fiberoptic Grading of Glottic View } \\
\hline
\end{tabular}

There were no statistically significant differences between the two groups with regard to the incidence of complications $(\mathrm{P}=0.52)$.

\section{DISCUSSION}

Supraglottic airway devices have produced a major change in anaesthesia practice and management of airway. They provide an airway intermediate between the facemask and tracheal tube in terms of anatomic position, invasiveness and security. ProSeal LMA is a modification of classic LMA with a 
gastric drainage tube placed lateral to the main airway tube. I-Gel is a single use, non-inflatable supraglottic airway device which has the ability to conform to the airway anatomical structures. The current study was conducted to compare and evaluate ProSeal LMA with I-Gel in paediatric patients undergoing general anaesthesia.

80 ASA physical status 1 and 2 patients aged 4-15 yrs. scheduled to undergo elective surgery under general anaesthesia were included for the study. The mean age of patients in our study was 8.71 years (group PLMA) and 8.24 years (group I-Gel). The mean weight of patients in our study was 22.12 in PLMA group and 24.78 in I-Gel group. Both males and females were adequately represented; $82 \%$ of the patients belonged to ASA physical status 1 and $18 \%$ of the patients ASA physical status 2.

Priya V and Collegues. ${ }^{8}$ conducted a study to compare conditions for LMA insertion, after induction of anaesthesia with either inhalation of sevoflurane or intravenous propofol. They concluded that propofol is better than sevoflurane for LMA insertion using the loss of eye lash reflex as the end point of induction. In our study, we used only propofol for insertion of LMA. After induction with propofol $3 \mathrm{mg} / \mathrm{kg}$, additional doses of propofol were given when jaw relaxation was inadequate. In our study, 17 patients required additional dose (10-20 mg) of propofol to achieve adequate jaw relaxation.

A previous study was done by Ansar Ali and co-workers to compare the ease of insertion of I-Gel and PLMA in adult patients. The ease of insertion was assessed in terms of number of attempts and the time taken for device insertion. They concluded that there was no significant difference between I-Gel and PLMA in terms of ease of inertion. ${ }^{9}$ In our study, the average time required for insertion for PLMA was 14.39 seconds and I-Gel 12.13 seconds, though the number of $1^{\text {st }}$ attempt success rates were similar in both the groups. The lesser insertion time for I-Gel group may be due to the reason that it is uncuffed.

In our study, clinical criteria of placement were satisfactory in $75 \%$ patients with I-Gel after first attempt of insertion; 4 patients had leak and clinically satisfactory placement was seen in all patients after second attempt. In PLMA group, clinical criteria were satisfactory in $83 \%$ patients after first attempt, 3 patients had leak and clinically satisfactory placement was seen in all patients after second attempt.

Fiberoptic glottic grading was statistically similar in both the groups (P value=0.731). Grade $3(n=10)$ and $4(n=4)$ views were more with I-Gel, but it was statistically insignificant. There was no change in the fiberoptic view at the end of the surgery in all patients. Grade 5 view was not seen in any of the patients. This is because of the protocol in our study, which requires proper placement of device clinically before fiberoptic grading.

\section{CONCLUSION}

We conclude that PLMA requires more time for insertion compared to I-Gel. However, the final cuff position of PLMA is similar to that of I-gel as assessed by fiberoptic bronchoscopy. As both devices are suitable for ventilation in children, they can be used as an effective alternative to endotracheal intubation.

\section{ACKNOWLEDGEMENT}

Foremost, I would like to express my sincere gratitude to my guide and advisor Dr. Avanish Bhandary, Associate Professor, Department of Anaesthesiology, for the continuous support for my study and research, for his patience, motivation, enthusiasm and immense knowledge. His guidance helped me all along the time of research and writing of this thesis. My heartfelt gratitude to Dr. Satheesh Kumar Bhandary, our honourable Dean for all his support and help throughout the study. I extend my sincere gratitude to my teachers Dr. Raveendra US, Dr. Gayathri Bhat, Dr. Sumalatha R Shetty, Dr. B. Jayaram Rai, Dr. Avanish Bhandary, Dr. Nikhil MP, Dr. Manjunath R Kamath, Dr. Krishna Prasad, Dr. Anil Shetty, Dr. Murali Krishna, Dr. Nithya C Achaiah, Dr. Akshaya Rai, Dr. Carol D’Silva, Dr. Tushar Patel, Dr. Rolita Lobo, Dr. Priya Naik, Dr. Anirban Roy, Dr. Rashmi Soori, Dr. Murali Shankar, Dr. Sapana Joshi and Dr. Soumya for their guidance, support and encouragement. I am gratified in expressing thanks to my post graduate colleagues for their cooperation and precious help. I am grateful to Dr. Srikanth $\mathrm{N}$ for all the assistance he provided with the statistical analysis. I would also like to thank our OT and nursing staff for their valuable help throughout the study. I thank all my friends for their constant help and encouragement. I would also like to thank the clinicians and the patients without whom the study would not have been possible. I cannot end without thanking my parents and family who have been a source of unconditional love, concern, support and strength all these years. Above all, I thank God for giving me the strength all along.

\section{REFERENCES}

1. Helmy AM, Atef HM, El-Taher EM, et al. Comparative study between I-gel, a new supraglottic airway device, and classical laryngeal mask airway in anaesthetized spontaneously ventilated patients. Saudi J Anaesth 2010;4:131-6.

2. Patel MG, Swadia VN, Bansal G. Prospective randomized comparative study of use of MA and ET tube for airway management in children under general anaesthesia. Indian J Anaesth 2010;54:109-15.

3. Martlew RA, Meakin G, Wadsworth R, et al. Dose of propofol for laryngeal mask airway insertion in children: effect of premedication with midazolam. British journal of anaesthesia 1996;76:308-309.

4. I-gel user guide. [http:/www.i-gel.com] -i-gel instruction manual 2007.

5. Dorsch and Dorsch, Understanding Anaesthesia Equipment. Park C, Bahk JH, Ahn WS, et al. 5th ed, Chapter 17, 2008:476.

6. Tokgoz O, Tufek A. Comparison of the efficacies of I-gel and LMA-proseal for airway management in paediatric patients. Turkish Journal of Medical Sciences 2013;43:208-213.

7. Park C, Bahk JH, Ahn WS, et al. The laryngeal mask airway in infants and children. Can J Anaesth 2001;48:413-7.

8. Priya, Divatia, Dasgupta. Propofol versus sevoflurane for LMA insertion. Indian J Anaesth 2002;46(1):31-4.

9. Ali A. Airway device: comparison of I-GEL supraglottic with laryngeal mask airway. Professional Med J 2010;17(4):643-7. 